\title{
Correlation of OPN gene expression with proliferation and apoptosis of ovarian cancer cells and prognosis of patients
}

\author{
HONGZHUAN HU ${ }^{1}$, ZHONGLAN LIU ${ }^{2}$ and CUN LIU ${ }^{3}$ \\ ${ }^{1}$ Department of Obstetrics, Shouguang People's Hospital, Weifang, Shandong 262700; \\ ${ }^{2}$ Department of Gynaecology, The People's Hospital of Qihe County, Qihe, Shandong 251100; \\ ${ }^{3}$ Department of Laboratory, Jining No. 1 People's Hospital, Jining, Shandong 272000, P.R. China
}

Received April 12, 2018; Accepted October 25, 2018

DOI: $10.3892 / \mathrm{ol} .2019 .9896$

\begin{abstract}
Correlation of osteopontin (OPN) gene expression with proliferation and apoptosis of ovarian cancer cells and prognosis of patients was investigated. The expression levels of OPN in 81 pairs of ovarian cancer tissues and para-carcinoma tissues obtained via surgical resection were detected using immunohistochemistry (IHC). The correlation of OPN protein expression with clinicopathological features of patients was analyzed. All patients were followed up for 3 years. The disease-free survival (DFS) and overall survival (OS) curves of patients in high/low OPN expression groups were drawn using the Kaplan-Meier method. The expression levels of OPN in normal ovarian epithelial IOSE80 cells and 5 ovarian cancer cell lines were detected via western blotting. Moreover, two cell lines with high OPN expression were interfered with lentiviral transfection technique. The effects of OPN on ovarian cancer cell proliferation and apoptosis were detected and analyzed via Cell Counting Kit-8 (CCK8) assay and flow cytometry. The positive expression rate of OPN protein in tumor tissues was higher than that in para-carcinoma tissues $(\mathrm{P}<0.05)$. Survival curves suggested that both DFS and OS in OPN negative group were superior to those in OPN positive group $(\mathrm{P}<0.05)$. Results of western blotting showed that OPN was weakly expressed in IOSE80 cells, whereas it was highly expressed in SKOV-3, COC1, A2780, HO-8910 and OVCAR-3 cells, among which the OPN protein expression levels were relatively higher in SKOV-3 and OVCAR-3 cell lines. After knockdown of OPN gene with sh-OPN, the cell proliferation rates of OVCAR-3 and SKOV-3 were significantly decreased from $48 \mathrm{~h}(\mathrm{P}<0.05)$, but the apoptosis level was increased remarkably ( 28.2 vs. $1.3 \%$ and 25.3 vs. $3.2 \%$ ), and differences were statistically significant $(\mathrm{P}<0.05)$. In conclusion,
\end{abstract}

Correspondence to: Dr Cun Liu, Department of Laboratory, Jining No. 1 People's Hospital, 6 Jiankang Road, Jining, Shandong 272000, P.R. China

E-mail: 1csd2018@163.com

Key words: OPN, ovarian cancer, proliferation, apoptosis, prognosis overexpression of OPN enhances the proliferation of ovarian cancer cells, which is an adverse factor for patient survival and prognosis.

\section{Introduction}

Ovarian cancer is a kind of common malignant gynecological tumor, whose mortality rate ranks 1st in all kinds of gynecological tumors (1). Due to the lack of typical clinical symptoms and specific clinical diagnostic indexes in the early stage, missed diagnosis easily occur. More than $80 \%$ of patients with ovarian cancer are in the middle-advanced stage at the initial diagnosis. Despite of the therapeutic regimen of cytoreductive surgery and postoperative chemotherapy currently, the 5-year survival rate of patients with ovarian cancer is still less than $40 \%$ (2). Therefore, searching effective molecular targets has always been a research hotspot in the treatment of ovarian cancer.

Osteopontin (OPN) is a phosphorylated glycoprotein that exists as a potential biomarker in the protein matrix of all body fluids, extracellular matrix (ECM) and mineralized tissues (3). Some studies suggest that the OPN levels may increase in tumor tissues and blood of patients, and there is evidence that the increased OPN may be associated with the reduced survival rate of patients $(4,5)$. Although the OPN expression has been widely studied, the role and exact mechanism of OPN in the occurrence, development and metastasis of ovarian cancer remain unclear.

In this study, the expression of OPN protein in ovarian cancer tissues was detected via immunohistochemistry (IHC) using clinical specimens, and the cytological study was further conducted, so as to clarify the biological role of OPN in ovarian cancer and investigate whether OPN can serve as a prognostic index of patients with ovarian cancer, thus becoming a candidate target for tumor treatment.

\section{Materials and methods}

Clinical data. A total of 81 patients with ovarian cancer without any previous treatment and treated in the Obstetrics Department of Shouguang People's Hospital (Weifang, China) from January 2010 to March 2013 were collected, and they were aged 32-76 years with an average of 46.8 years. In 
terms of the pathological type, there were 35 cases of serous cystadenocarcinoma, 32 cases of mucous cystadenocarcinoma, 11 cases of endometrioid carcinoma, and 3 cases of other types. In terms of cytological grading, there were 18 cases of well-differentiated carcinoma, 26 cases of moderatelydifferentiated carcinoma, and 37 cases of poorly-differentiated carcinoma. According to the new pathological staging criteria of the International Federation of Gynecology and Obstetrics (FIGO) in 2012, there were 24 cases in stage I, 29 cases in stage II, 16 cases in stage III, and 12 cases in stage IV.

Inclusion criteria: i) patients pathologically diagnosed with epithelial ovarian cancer and receiving surgical treatment, ii) patients without receiving any treatment before operation, and iii) patients with complete clinical data. All patients were followed up for 3 years.

This study was approved by the Ethics Committee of Shouguang People's Hospital, and all patients enrolled in this study signed the informed consent.

Detection of OPN protein expression via IHC. Paraffinembedded specimens of ovarian cancer tissues in 81 patients were collected from the Pathology Department, Shouguang People's Hospital, fixed with $40 \%$ formaldehyde at $22^{\circ} \mathrm{C}$ for $12 \mathrm{~h}$ and then cut into $4 \mu \mathrm{m}$-thick sections. Hematoxylin and eosin (H\&E) were used for $\mathrm{H} \& \mathrm{E}$ staining, followed by histopathological observation. Then pathologically-confirmed ovarian cancer tissues and para-carcinoma tissues (more than $4 \mathrm{~cm}$ ) were taken and serially sliced into $4 \mu \mathrm{m}$-thick sections, followed by OPN IHC staining. In IHC, two-step method and universal kit (model: ZLI9610; Beijing Zhongshan Golden Bridge Biotechnology Co., Ltd., Beijing, China) were used. Tissues were blocked with $8 \%$ milk at $4^{\circ} \mathrm{C}$ for $2 \mathrm{~h}$. The primary goat anti-mouse polyclonal antibody of OPN (dilution, 1:800; cat. no. AF808) and the secondary Donkey anti-goat polyclonal antibody (dilution, 1:2,000; cat. no. VC004) were purchased from R\&D Systems, Inc. (Minneapolis, MN, USA). The primary antibody was replaced with phosphate buffered saline (PBS) as the negative control. IHC results were interpreted independently by two pathologists. Nuclei or cytoplasm stained dark brown indicated positive IHC results. Five fields of view were selected randomly under a high-power microscope (magnification, x400; Olympus, Tokyo, Japan), followed by scoring based on the proportion of positive cells in each field of view and staining intensity: proportion of positive cells $<5 \%$ ( 0 point), $5-30 \%$ (1 point), $31-70 \%$ ( 2 points) and $>70 \%$ ( 3 points), and staining intensity: negative ( 0 point), weak ( 1 point), moderate ( 2 points) and strong ( 3 points). The above two scores were added up, and the final score $>3$ points indicated positive expression.

Detection of OPN protein expression via western blotting. After $200 \mu \mathrm{l}$ mixed solution (1:10) containing protease inhibitor cocktail and protein lysis buffer RIPA was added into a 6-well plate, the cell lysis buffer was taken into an EP tube and centrifuged at $12,000 \mathrm{x} \mathrm{g}$ and $4^{\circ} \mathrm{C}$ for $30 \mathrm{~min}$. The protein concentration was determined using the bicinchoninic acid (BCA) protein assay kit (Beyotime, Guangzhou, China). A total of $10 \mu \mathrm{g}$ protein was added in each lane. After $40 \mu \mathrm{g}$ total protein was isolated via $20 \%$ sodium dodecyl sulfatepolyacrylamide gel electrophoresis, it was transferred onto a polyvinylidene fluoride (PVDF) membrane. The membrane was blocked with $5 \% \mathrm{BSA}$ at $20^{\circ} \mathrm{C}$ for $1.5 \mathrm{~h}$. The primary mouse anti-human antibody of OPN (dilution, 1:2,000; cat. no. 1433-OP-050/CF; R\&D Systems, Inc.) and glyceraldehyde-3-phosphate dehydrogenase (GAPDH) monoclonal antibody (dilution, 1:1,000; cat. no. 9484; Abcam, Cambridge, UK) were incubated at $4^{\circ} \mathrm{C}$, followed by incubation with the corresponding horseradish peroxidaselabeled secondary goat anti-mouse polyclnonal antibody (dilution, 1:2,000; cat. no. A0216; Beyotime, Shanghai, China) at room temperature for $1 \mathrm{~h}$. Finally, the membrane was visualized using the enhanced chemiluminescence (ECL) detection system (Bio-Rad Laboratories, Inc., Hercules, CA, USA) and the gray-scale analysis was performed using a gel analyzer.

\section{Lentivirus transfection}

Cell culture. Human epithelial ovarian cancer cell lines (SKOV-3, COC1, A2780, HO-8910 and OVCAR-3) were purchased from Bnbio (cat. nos. ATCC HTB-77, BNCC101678, BNCC100884, BNCC100717 and BNCC338624, Beijing, China). IOSE80 cell line was purchased from Wuhan Cell Bank, Chinese Academy of Sciences (Wuhan, China). Lipofectamine 2000 was from Invitrogen; Thermo Fisher Scientific, Inc. (Waltham, MA, USA). Roswell Park Memorial Institute (RPMI)-1640 culture solution and fetal bovine serum (FBS) were from Gibco; Thermo Fisher Scientific, Inc. All cells were inoculated into the RPMI-1640 medium containing $10 \%$ FBS and cultured in an incubator with $5 \%$ $\mathrm{CO}_{2}$ at $37^{\circ} \mathrm{C}$. Cells in the logarithmic growth phase were taken for subsequent experiments.

Cell transfection. According to the manufacturer's instructions, short hairpin ribonucleic acid (sh-RNA) solution was mixed with Lipofectamine 2000 at a volume ratio of 1:1. Cells were divided into sh-vector group (transfected with negative control sequence) and sh-OPN group (transfected with targeted OPN sequence). One targeted OPN sequence (sh-OPN) and one negative control sequence (sh-vector) were designed and synthesized by Shanghai GenePharma Co., Ltd. (Shanghai, China). Targeted OPN sequence (sh-OPN): sense strand: 5'-GGGACUGGAAUACGCUAAUTT-3', antisense strand: 5'-AUUAGCGUAUUCCAGUCCCTT-3'. Negative control (sh-vector) sequence: sense strand: 5'-UUCUCCGAACGU GUCACGUTT-3', antisense strand: 5'-ACGUGACACGUU CGGAGAATT-3'. After successful transfection, cells continued to be incubated in the incubator, and western blotting was used to identify the interference effect after $48 \mathrm{~h}$ (not shown here).

Detection of cell proliferation via cell counting kit 8 (CCK8) assay. Cells in the logarithmic growth phase were taken, inoculated into a 96 -well plate $\left(1 \times 10^{3} /\right.$ well) and cultured, followed by CCK- 8 assay at $6,12,24,48$ and $72 \mathrm{~h}$. CCK- 8 solution $(100 \mu \mathrm{l})$ diluted with RPMI-1640 medium was added into each well, followed by incubation in a dark place at $37^{\circ} \mathrm{C}$ for $2 \mathrm{~h}$. Then the optical density was read at $450 \mathrm{~nm}$ using a microplate reader (Bio-Rad Laboratories, Inc.). Three repeated wells were set in each group. The growth curve was drawn after measurement for 7 consecutive days. 

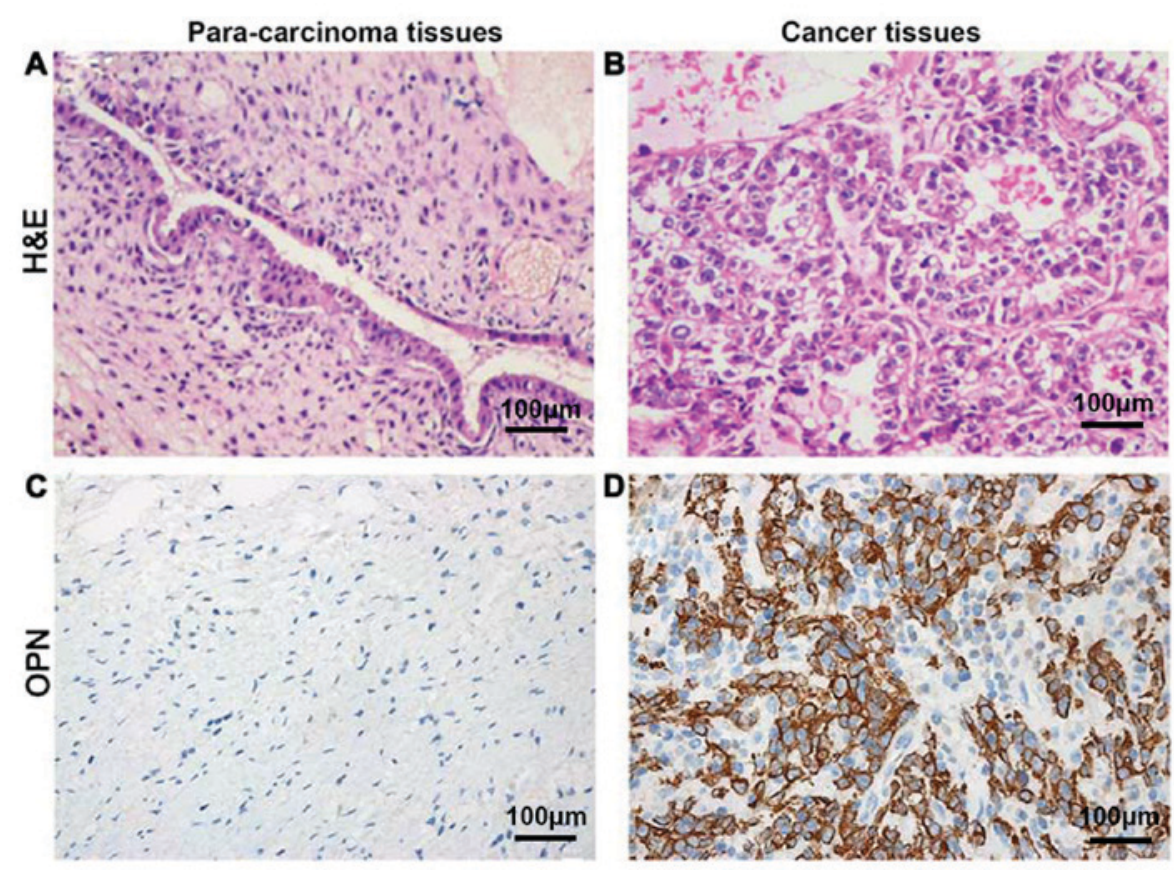

Figure 1. Detection of OPN expression levels in cancer tissues and para-carcinoma tissues via H\&E and IHC. Cancer and para-carcinoma tissues of the same patient are shown (A-D). (A and B) Clear cell adenocarcinoma is shown in H\&E staining, and cells in the lesion region display the cystic, papillary and hyaline changes. (C) The negative expression of OPN. (D) OPN is located in the cytoplasm, and the expression is strongly positive. OPN, osteopontin.

Detection of apoptosis level via flow cytometry. The apoptosis level in each group of cells was detected using the apoptosis kit (Harlingen; BD Biosciences, Franklin Lakes, NJ, USA). After cells were treated with different extract liquids for $48 \mathrm{~h}$, the cell culture fluid was taken and retained, and then cells were centrifuged at $800 \mathrm{x}$ g for $5 \mathrm{~min}$, washed with PBS, centrifuged again twice, and resuspended in $100 \mu \mathrm{l} 1 \mathrm{X}$ binding buffer. Then $5 \mu \mathrm{l}$ propidium iodide (PI) and $5 \mu \mathrm{l}$ Annexin $\mathrm{V}$ were added, followed by incubation in the dark at room temperature for $15 \mathrm{~min}$. Then the mixture was sent to the scientific research center for on-machine detection within $1 \mathrm{~h}$. Apoptotic rate = early apoptotic rate + late apoptotic rate.

Statistical analysis. GraphPad Prism software (version 5.01, GraphPad Software, Santiago, Chile) was used for analysis. Chi-square test was used for the correlation of OPN expression with clinicopathological data of patients. The disease-free survival (DFS) and overall survival (OS) curves of patients in high/low OPN expression groups were drawn using the Kaplan-Meier method. The survival difference was compared between the two groups of patients using the log-rank test, and the differences in indexes were compared between the two groups via independent $\mathrm{t}$-test. $\mathrm{P}<0.05$ was considered to indicate a statistically significant difference.

\section{Results}

Detection of OPN expression levels in cancer and paracarcinoma tissues via IHC. OPN was located in the cytoplasm. The positive expression rate of OPN protein in tumor tissues was $77.8 \%$ (63/81), which was significantly higher than that in para-carcinoma tissues $11.1 \%(9 / 81)$, showing a statistically significant difference $(\mathrm{P}<0.05)$ (Fig. 1).
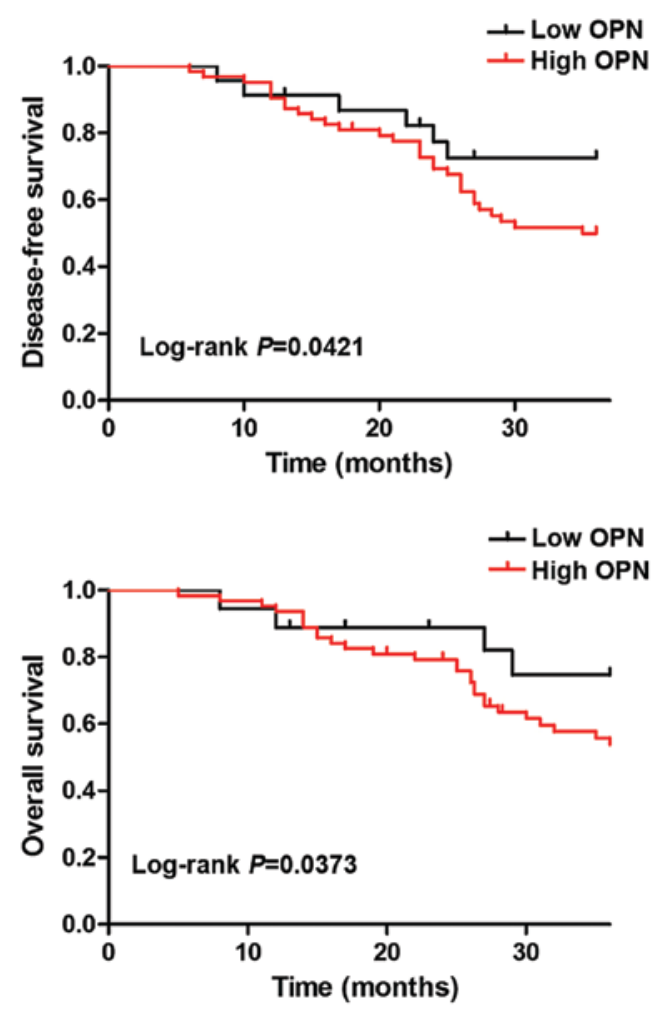

Figure 2. Correlation of OPN protein expression with DFS and OS of patients with ovarian cancer. OPN, osteopontin; DFS, disease-free survival; OS, overall survival.

Correlation of OPN protein expression in ovarian cancer tissues with clinicopathological factors of patients. According to the IHC score, 63 patients were defined as OPN positive and 18 patients as OPN negative. Results of Chi-square test revealed that there were no significant 
Table I. Correlation of OPN protein level in ovarian cancer tissues with pathological indexes of patients.

\begin{tabular}{|c|c|c|c|c|c|}
\hline \multirow[b]{2}{*}{ Parameters } & \multirow[b]{2}{*}{$\mathrm{n}=81$} & \multicolumn{2}{|c|}{ OPN } & \multirow[b]{2}{*}{$\chi^{2}$ value } & \multirow[b]{2}{*}{ P-value } \\
\hline & & $\begin{array}{l}\text { High expression } \\
\qquad(\mathrm{n}=63)\end{array}$ & $\begin{array}{l}\text { Low expression } \\
\qquad(\mathrm{n}=18)\end{array}$ & & \\
\hline Sex & & & & 1.74 & 0.271 \\
\hline Male & 47 & $35(74.5)$ & $12(25.5)$ & & \\
\hline Female & 34 & $28(82.3)$ & $6(17.7)$ & & \\
\hline Age (years) & & & & 1.15 & 0.364 \\
\hline$\leq 45$ & 38 & $28(73.7)$ & $10(26.3)$ & & \\
\hline$>45$ & 43 & $35(81.4)$ & $8(18.6)$ & & \\
\hline Pathological type & & & & 2.23 & 0.156 \\
\hline Serous & 20 & $11(55.0)$ & $9(45.0)$ & & \\
\hline Non-serous & 62 & $52(83.9)$ & $10(16.1)$ & & \\
\hline FIGO staging & & & & 6.95 & 0.019 \\
\hline $\mathrm{I}+\mathrm{II}$ & 53 & $38(71.7)$ & $15(28.3)$ & & \\
\hline III+IV & 28 & $25(89.3)$ & $3(10.7)$ & & \\
\hline Cytological differentiation & & & & 6.43 & 0.025 \\
\hline G1 & 18 & $12(66.7)$ & $6(33.3)$ & & \\
\hline $\mathrm{G} 2$ & 26 & $18(69.3)$ & $8(30.7)$ & & \\
\hline G3 & 37 & $33(89.2)$ & $4(10.8)$ & & \\
\hline Tumor metastasis & & & & 7.86 & 0.009 \\
\hline Negative & 50 & $37(74.0)$ & $13(26.0)$ & & \\
\hline Positive & 31 & $26(83.9)$ & $5(16.1)$ & & \\
\hline
\end{tabular}

Bold, statistically significant difference.

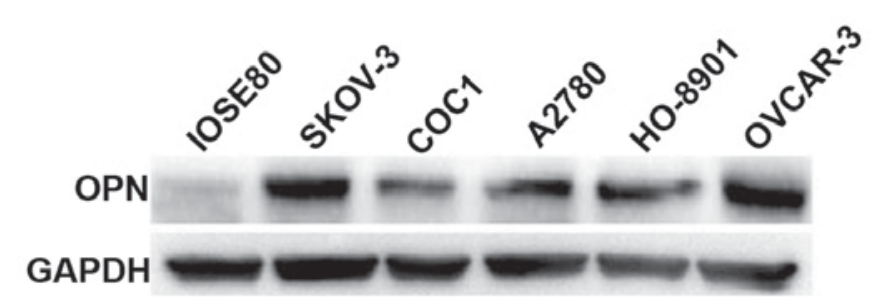

Figure 3. Detection of OPN expression levels in normal ovarian epithelial and cancer cells via western blotting. OPN, osteopontin.

differences in the positive rate of OPN protein in ovarian cancer tissues among patients with different age, sex and tumor progression $(\mathrm{P}>0.05)$. Compared with that in patients with early ovarian cancer (stage I+II), the positive expression rate of OPN in patients with middle-advanced ovarian cancer (stage III+IV) was significantly increased (89.3 vs. $71.7 \%$, $\left.\chi^{2}=6.95, \mathrm{P}=0.019\right)$. Besides, the positive expression rates of OPN in ovarian cancer tissues in well-differentiated group, moderately-differentiated group and poorly-differentiated group were $66.7,69.3$ and $89.2 \%$, respectively. The positive expression rate of OPN was gradually increased with the decreased degree of cell differentiation, and differences were statistically significant $(\mathrm{P}<0.05)$. The positive rate of OPN in metastatic ovarian cancer tissues was obviously higher than that in non-metastatic ovarian cancer tissues (83.9 vs. $74.0 \%$, $\chi^{2}=7.86, \mathrm{P}=0.009$ ) (Table I).
Correlation of OPN expression with prognosis of patients with ovarian cancer. Survival analysis was performed using the Kaplan-Meier method, and DFS and OS were compared via the log-rank test. Both DFS and OS of patients in OPN negative group were superior to those in OPN positive group, and there were statistically significant differences $(\mathrm{P}<0.05)$ (Fig. 2).

Detection of OPN expression levels in normal ovarian epithelial and cancer cells via western blotting. The expression levels of OPN in normal ovarian epithelial IOSE80 cells and 5 ovarian cancer cell lines (SKOV-3, COC1, A2780, HO-8910 and OVCAR-3) were detected via western blotting. Results revealed that OPN was weakly expressed in IOSE80 cells, whereas it was highly expressed in 5 ovarian cancer cell lines, among which the OPN protein expression levels were relatively higher in SKOV-3 and OVCAR-3 cell lines (Fig. 3).

Effect of lentivirus interference in OPN on cell proliferation capacity. Results of CCK8 assay demonstrated that the cell proliferation rates of OVCAR-3 and SKOV-3 cells were decreased remarkably from $48 \mathrm{~h}$ after OPN gene knockout with sh-OPN, and differences were statistically significant $(\mathrm{P}<0.05)$ (Fig. 4).

Effect of OPN knockout on apoptosis level. After OPN gene knockout with sh-OPN, the apoptosis levels of OVCAR-3 and SKOV-3 cells were obviously increased (28.2 vs. $1.3 \%$ and 

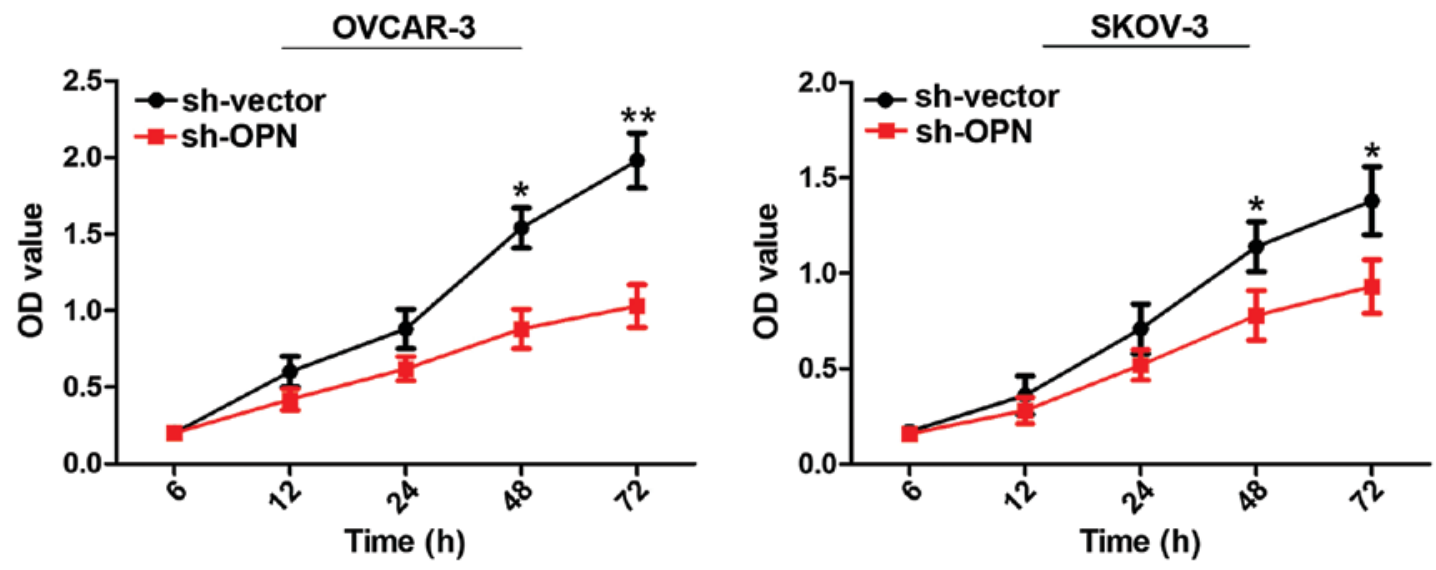

Figure 4. Effect of lentivirus interference in OPN on cell proliferation capacity. OPN, osteopontin. ${ }^{*} \mathrm{P}<0.05 ;{ }^{* *} \mathrm{P}<0.01$.
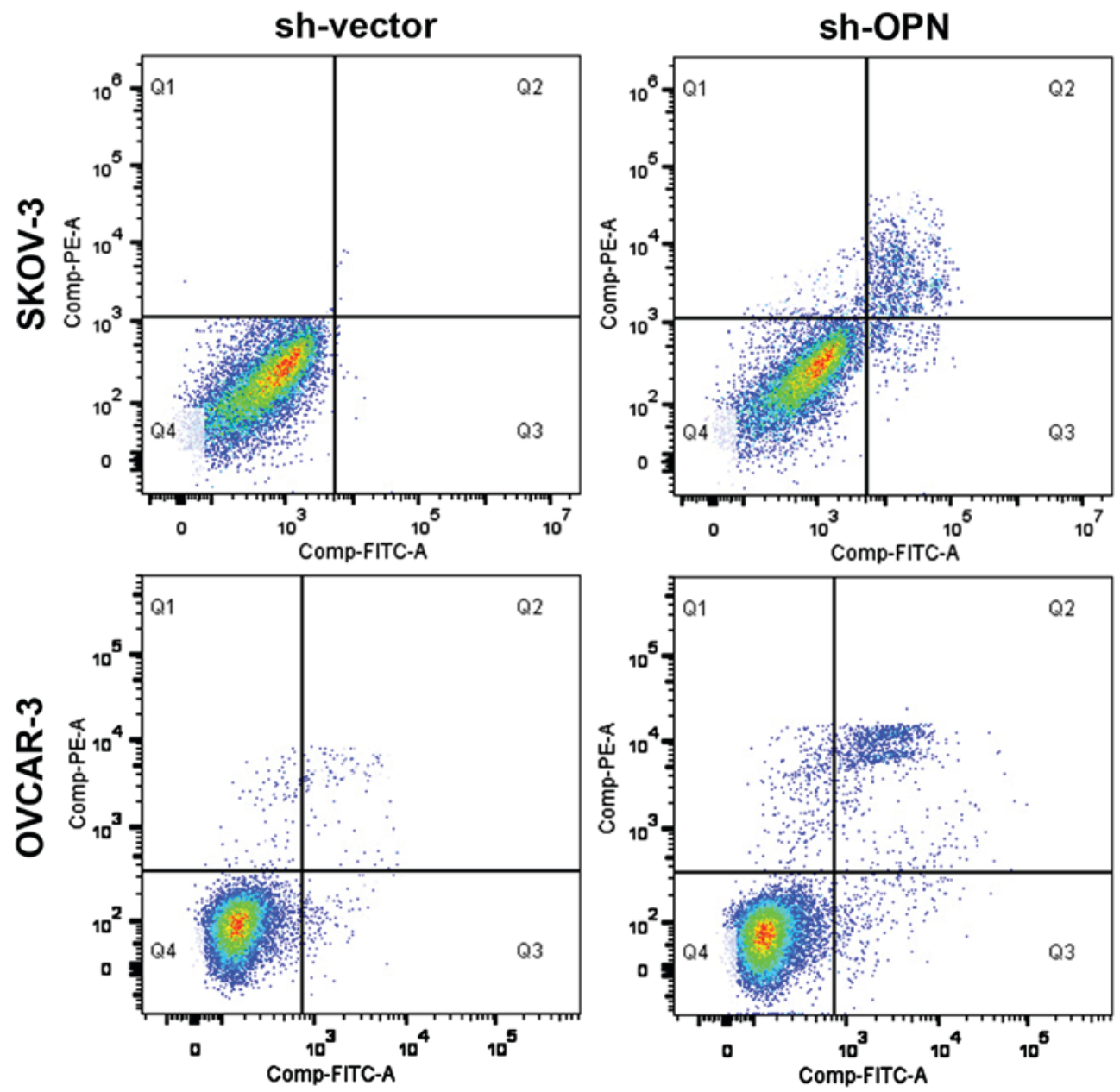

Figure 5. OPN knockout obviously inhibits the apoptosis capacity. OPN, osteopontin.

25.3 vs. $3.2 \%$ ), and there were statistically significant differences $(\mathrm{P}<0.05)$ (Fig. 5).

\section{Discussion}

OPN protein was described for the first time as a marker of epithelial cell transformation, and there has been considerable interest in the role of OPN in human tumorigenesis subsequently. OPN is both a marker of malignant tumors and a candidate for detection as a prognostic factor (6). The OPN expression is detected via IHC in tumor tissues of lung cancer, breast cancer, prostate cancer, gastric cancer, esophagus cancer, glioma and other human cancers $(7,8)$. In a study of 25 cases of lung tumor specimens, it was found that both OPN mRNA and protein levels are elevated compared with those in normal lung tissues, and the positive rate of OPN protein has statistical significance in the survival of patients (9). In a recent study, tissue specimens of 68 patients with primary 
breast cancer, metastatic tumor and fibroadenoma, and normal subjects were studied, and results manifested that OPN mRNA and protein levels are increased in malignant tissues compared with those in benign/normal tissues, and the positive tumor cell immunity is associated with local recurrence and metastasis of tumors formed in the liver and bone (10). However, there is still a lack of studies on the expression and biological effects of OPN protein in ovarian cancer.

In this study, the expression levels of OPN protein in 81 pairs of ovarian cancer tissues and para-carcinoma tissues were detected via IHC. Based on the immunostaining score of 3 points, 63 cases were defined as OPN positive and 18 cases as OPN negative. Results of Chi-square test revealed that there were no significant differences in the positive rate of OPN protein in ovarian cancer tissues among patients with different age, sex and tumor progression $(\mathrm{P}>0.05)$. Compared with that in patients with early ovarian cancer (stage I+II), the positive expression rate of OPN in patients with middle-advanced ovarian cancer (stage III+IV) was significantly increased (89.3 vs. $\left.71.7 \%, \chi^{2}=6.95, \mathrm{P}=0.019\right)$. Besides, the positive expression rates of OPN in ovarian cancer tissues in well-differentiated group, moderately-differentiated group and poorly-differentiated group were 66.7, 69.3 and $89.2 \%$, respectively. The positive expression rate of OPN was gradually increased with the decreased degree of cell differentiation, and differences were statistically significant $(\mathrm{P}<0.05)$. The positive rate of OPN in metastatic ovarian cancer tissues was obviously higher than that in non-metastatic ovarian cancer tissues (83.9 vs. $74.0 \%, \chi^{2}=7.86, \mathrm{P}=0.009$ ). The above results are consistent with the research results of Yeatman and Chambers on colon cancer (11).

In addition, all the patients enrolled were followed up for 3 years, and DFS and OS curves were drawn using KaplanMeier method. Results manifested that there were negative correlations of baseline OPN level with DFS and OS, and the increased OPN level had a significant correlation with the mortality risk over time. Such a result is similar to that of Donati et al who found that the positive rate of OPN is significantly associated with the survival of patients with lung cancer (12). Moreover, in a study involving 163 patients with prostate cancer who were followed up for at least 6 years, it was demonstrated that the high expression level of OPN is an extremely adverse prognostic factor for OS and DFS, and the expression of OPN is proved to be remarkably associated with OS and DFS in univariate and multivariate analyses (13).

OPN is expressed and secreted by a variety of cells (osteoclasts, fibroblasts, macrophages and tumor cells), which possess a variety of functions, and play an important role in cell adhesion, chemotaxis, prevention of apoptosis, invasion, migration, and anchorage-independent growth of tumor cells $(14,15)$. Previous studies mostly focused on the correlations of OPN with invasion and metastasis of tumor cells. Studies have found that the signal transduction after OPN activates the cell surface receptors can increase the expression of proteolytic enzymes that can degrade ECM proteins, especially matrix metalloproteinases (MMPs) and urokinase plasminogen activator (UPA), thus enhancing invasiveness $(16,17)$. In addition, OPN selectively induces CD44-dependent chemotaxis, the latter of which contributes to tumor cell migration and invasion (18). Recent studies have displayed that after treatment of colon cancer cells with OPN, the cell proliferation capacity is significantly enhanced, and OPN can protect suspensioncultured liver cancer cells from stress-induced apoptosis (19). Gong et al added OPN into gastric cancer cell lines to resist ultraviolet-induced apoptosis, which has been proved to be mediated through binding to the $\alpha v \beta 3$ integrin receptor, thereby, in turn, activating the transcription factor nuclear factor $\kappa-\mathrm{B}$ (NFк-B) to exert biological effects (20).

In this study, the expression levels of OPN in normal ovarian epithelial IOSE80 cells and 5 ovarian cancer cell lines (SKOV-3, COC1, A2780, HO-8910 and OVCAR-3) were detected via western blotting. Results revealed that the expression levels of OPN in 5 ovarian cancer cell lines were obviously higher than that in normal ovarian epithelial cells. Furthermore, the OPN genes in SKOV-3 and OVCAR-3 cell lines with higher OPN protein expression were knocked out using the lentivirus. Subsequently, CCK8 assay and flow cytometry demonstrated that OPN knockdown significantly inhibited the cell proliferation level, whose mechanism might be mediated through inducing apoptosis.

In conclusion, OPN is highly expressed in ovarian cancer tissues, and overexpressed OPN enhances ovarian cancer cell proliferation, which is an adverse factor for the survival and prognosis of patients with ovarian cancer. Targeting OPN has potential significance in providing new treatment opportunity for patients with ovarian cancer.

\section{Acknowledgements}

Not applicable.

\section{Funding}

No funding was received.

\section{Availability of data and material}

The datasets used and/or analyzed during the current study are available from the corresponding author on reasonable request.

\section{Authors' contributions}

$\mathrm{HH}$ wrote the manuscript and was responsible for cell culture. ZL performed cell transfection. CL contributed to CCK8 assay. All authors read and approved the final manuscript.

\section{Ethics approval and consent to participate}

The study was approved by the Ethics Committee of Shouguang People's Hospital (Weifang, China) and informed consents were signed by the patients or guardians.

\section{Patient consent for publication}

Not applicable.

\section{Competing interests}

The authors declare that they have no competing interests. 


\section{References}

1. Patch AM, Christie EL, Etemadmoghadam D, Garsed DW, George J, Fereday S, Nones K, Cowin P, Alsop K, Bailey PJ, et al Australian Ovarian Cancer Study Group: Whole-genome characterization of chemoresistant ovarian cancer. Nature 521: 489-494, 2015

2. Jacobs IJ, Menon U, Ryan A, Gentry-Maharaj A, Burnell M, Kalsi JK, Amso NN, Apostolidou S, Benjamin E, Cruickshank D, et al: Ovarian cancer screening and mortality in the UK Collaborative Trial of Ovarian Cancer Screening (UKCTOCS): A randomised controlled trial. Lancet 387 : 945-956, 2016.

3. Anborgh PH, Mutrie JC, Tuck AB and Chambers AF: Pre- and post-translational regulation of osteopontin in cancer. J Cell Commun Signal 5: 111-122, 2011.

4. Ue T, Yokozaki H, Kitadai Y, Yamamoto S, Yasui W, Ishikawa T and Tahara E: Co-expression of osteopontin and CD44v9 in gastric cancer. Int J Cancer 79: 127-132, 1998.

5. Agrawal D, Chen T, Irby R, Quackenbush J, Chambers AF, Szabo M, Cantor A, Coppola D and Yeatman TJ: Osteopontin identified as lead marker of colon cancer progression, using pooled sample expression profiling. J Natl Cancer Inst 94: 513-521, 2002.

6. Weber GF: The metastasis gene osteopontin: A candidate target for cancer therapy. Biochim Biophys Acta 1552: 61-85, 2001.

7. Rudland PS, Platt-Higgins A, El-Tanani M, De Silva Rudland S, Barraclough R, Winstanley JH, Howitt R and West CR: Prognostic significance of the metastasis-associated protein osteopontin in human breast cancer. Cancer Res 62: 3417-3427, 2002.

8. Thalmann GN, Sikes RA, Devoll RE, Kiefer JA, Markwalder R, Klima I, Farach-Carson CM, Studer UE and Chung LW: Osteopontin: Possible role in prostate cancer progression. Clin Cancer Res 5: 2271-2277, 1999.

9. Chambers AF, Wilson SM, Kerkvliet N, O'Malley FP, Harris JF and Casson AG: Osteopontin expression in lung cancer. Lung Cancer 15: 311-323, 1996.

10. Rodrigues LR, Teixeira JA, Schmitt FL, Paulsson M and Lindmark-Mänsson $\mathrm{H}$ : The role of osteopontin in tumor progression and metastasis in breast cancer. Cancer Epidemiol Biomarkers Prev 16: 1087-1097, 2007.
11. Yeatman TJ and Chambers AF: Osteopontin and colon cancer progression. Clin Exp Metastasis 20: 85-90, 2003.

12. Donati V, Boldrini L, Dell'Omodarme M, Prati MC, Faviana P, Camacci T, Lucchi M, Mussi A, Santoro M, Basolo F, et al: Osteopontin expression and prognostic significance in non-small cell lung cancer. Clin Cancer Res 11: 6459-6465, 2005.

13. Khodavirdi AC, Song Z, Yang S, Zhong C, Wang S, Wu H, Pritchard C, Nelson PS and Roy-Burman P: Increased expression of osteopontin contributes to the progression of prostate cancer. Cancer Res 66: 883-888, 2006.

14. He B, Mirza M and Weber GF: An osteopontin splice variant induces anchorage independence in human breast cancer cells. Oncogene 25: 2192-2202, 2006.

15. Katagiri YU, Sleeman J, Fujii H, Herrlich P, Hotta H, Tanaka K, Chikuma S, Yagita H, Okumura K, Murakami M, et al: CD44 variants but not $\mathrm{CD} 44 \mathrm{~s}$ cooperate with beta1-containing integrins to permit cells to bind to osteopontin independently of arginine-glycine-aspartic acid, thereby stimulating cell motility and chemotaxis. Cancer Res 59: 219-226, 1999.

16. Liu H, Chen A, Guo F and Yuan L: A short-hairpin RNA targeting osteopontin downregulates MMP-2 and MMP-9 expressions in prostate cancer PC-3 cells. Cancer Lett 295: 27-37, 2010.

17. Buommino E, De Filippis A, Gaudiello F, Balato A, Balato N, Tufano MA and Ayala F: Modification of osteopontin and MMP-9 levels in patients with psoriasis on anti-TNF- $\alpha$ therapy. Arch Dermatol Res 304: 481-485, 2012.

18. Desai B, Rogers MJ and Chellaiah MA: Mechanisms of osteopontin and CD44 as metastatic principles in prostate cancer cells. Mol Cancer 6: 18, 2007.

19. Gotoh M, Sakamoto M, Kanetaka K, Chuuma M and Hirohashi S: Overexpression of osteopontin in hepatocellular carcinoma. Pathol Int 52: 19-24, 2002.

20. Gong M, Lu Z, Fang G, Bi J and Xue X: A small interfering RNA targeting osteopontin as gastric cancer therapeutics. Cancer Lett 272: 148-159, 2008

This work is licensed under a Creative Commons Attribution-NonCommercial-NoDerivatives 4.0 International (CC BY-NC-ND 4.0) License. 